\title{
De la devoción al interés político
}

Laura B. Suárez de la Torre

INSTITUTO MORA

Expone las intenciones espirituales y temporales

de la autoridad eclesiástica expresadas en la folletería publicada entre 1837 y 1851.

$\mathrm{U}$ na vez que el país logró su independencia, el debate político acaparó la atención de quienes se interesaron en conducir a la nueva nación.

Ante la carencia de opciones periodisticas [...] todo aquel que deseara decir algo, y podía costearlo, mandaba imprimir un folleto al taller de su preferencia, resultando de ahí publicaciones de la más variada índole que por su llaneza, agresividad e, incluso, sentido del humor, mucho contrastan con la austeridad casi monotemática de los textos impresos durante la época colonial. ${ }^{1}$

${ }^{1}$ Muriá, "Folletería", 1986, p. 5
De ese modo, la folletería sirvió como un medio eficaz para dar a conocer la ideología de distintos sectores de la sociedad. Permeó las ideas de los diversos poderes que se disputaban el escenario nacional y circuló por diferentes sitios del país como una manera fácil y barata de dar a conocer, primordialmente, los principios políticos y los asuntos judiciales. Mas no únicamente las cuestiones de esta indole fueron expuestas en los folletos, también circularon los preceptos religiosos, los temas educativos, los avances científicos, las novedades económicas, los ensayos literarios, entre otros, y se constituyeron en un importante 
medio para denunciar o defender a personas e instituciones. Por ello, a lo largo del sigho XIX encontramos una enorme producción de opúsculos que respondió a las necesidades del momento.

Los años comprendidos entre 1837 y 1851 son una etapa plena dé acontecimientos en la historia de México en los que se experimentaron el ensayo centralista, la vuelta al federalismo, las consecuentes guerras civiles, los conflictos de castas, la recesión económica, las invasiones extranjeras, así como la pérdida de territorio nacional. Fue un tiempo en el que los mexicanos no se dieron descanso, y tuvieron que enfrentar los diversos acontecimientos e inventar, de alguna manera, el país en que estaban viviendo, sus instituciones y sus relaciones con las diversas entidades heredadas de la época colonial. Sin duda que ese tiempo fue de una riqueza desbordante en el plano político, pues quienes se encontraron al frente de los negocios nacionales -estadistas, abogados y aspirantes a puestos de elección popularestaban probando la suerte de la nación desde diversas perspectivas. ${ }^{2}$ En ese contexto, la Iglesia fue constantemente aludida, pues su presencia era una realidad insoslayable a la que se enfrentó el nuevo Estado mexicano. De hecho, puede decirse que había regido a la sociedad, como señala Brian Connaughton, pues "representaba un conducto clave en la continuidad ideológica de la sociedad mexicana". ${ }^{3}$ No hay que perder de vista que, a lo largo

2 Connaughton, Ideología, 1992, p. 53.

${ }^{3}$ Ibid., p. 42. de casi trescientos años, los clérigos habían establecido una relación casi inseparable en la vida cotidiana de los novohispanos marcando las pautas de conducta, manejando la educación, conduciendo, en parte, las actividades económicas y que, al darse la independencia, esta situación parecía no variar, aunque con el paso del tiempo la realidad empujó a aclarar los campos de acción de las dos entidades que se disputaban el poder: el Estado en ciernes y la potestad eclesiástica que tenía una larga trayectoria en el territorio otrora novohispano. ${ }^{4}$

Desde esta perspectiva, en el nuevo experimento nacional los religiosos tuvieron una presencia importante, a la vez que, preocupados por su grey, entraron a conformar los diversos congresos y compitieron en diversos cargos públicos haciendo compatible su quehacer espiritual con el político. No obstante esa oportunidad para integrarse en el nuevo panorama nacional, la Iglesia comenzó a ver afectados sus espacios de actuación y a temer un desplazamiento. Frente a esta posición, distinta necesariamente a la que experimentó a lo largo de la época colonial, tuvo que delinear una serie de estrategias que le permiticran mantener un sitio relevante en la vida nacional. Muy pronto

se aprecia el esfuerzo del clero por acoplarse ventajosamente al nuevo rumbo del país y a través del discurso elaborado por miembros de la Iglesia [...] en las

\footnotetext{
${ }^{4}$ Junto a estas dos entidades se encontraba un tercer poder, el ejército, que también disputó un espacio dentro del ámbito político mexicano.
} 


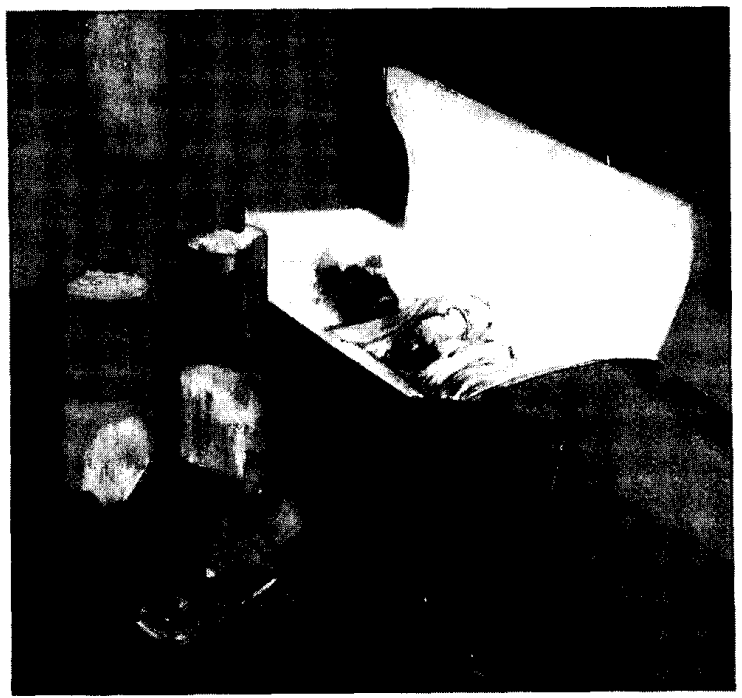

distintas coyunturas políticas -incluso sus inconsistencias, sus contradicciones y su variabilidad-, se pueden medir los esfuerzos de la Iglesia por imbricarse en el concierto de las fuerzas sociales dominantes en la épocabajo estudio[... $]^{5}$

De ese modo, si bien dentro de los templos -en sermones o en cartas pastorales- se manifestó la posición de la Iglesia, fuera de ellos encontró en la folletería otro medio eficaz para difundir sus principios, defender los derechos y prerrogativas que había logrado acumular a lo largo de tres siglos de presencia en Nueva España y definir su posición frente al Estado, 64.

5 Connaughton, Ideología, 1992, pp. 63 y

DE LA DEVOCIÓN AL INTERÉS POLITITCO que cada día ganaba un mayor espacio en la sociedad mexicana. ${ }^{6}$ Así, la producción de folletería eclesiástica se enriqueció y presentó una gran variedad de temas que reflejan, al mismo tiempo, las diversas preocupaciones de la institución tanto en su aspecto

${ }^{6}$ En el proyecto de Folletería Mexicana del Siglo XIX se agruparon los documentos de la Iglesia en las siguientes categorías: aranceles/ congruas/obvenciones; bienes de la Iglesia; cartas pastorales; catecismos/obras morales; cefebraciones; circulares/edictos episcopales; culto mariano; culto de los santos/cofradias; derecho canónico; documentos políticos Iglesia-Rstado; documentos pontificios; historia de la Iglesia; informes/memorias; noticias parroquiales; or:ciones; órdenes religiosas/congregaciones; organización de la Iglesia, polémica, seminarios/ colegios religiosos; sermón; teología/puntos de doctrina, y otros. 
espiritual como terrenal. Es, asimismo, un termómetro que permite evaluar las relaciones que planteó frente a las autoridades gubernamentales y reconocer los intereses materiales que defendió.

Al analizar la producción eclesiástica encontramos diversos rubros que nos permiten reconocer cuáles fueron los problemas y las intenciones de la Iglesia a lo largo del periodo al que hacemos referencia. Cabe señalar que, lógicamente, los aspectos espirituales sobrepasan a los terrenales, pues la mayor parte de la producción se refiere a oraciones, sermones o cartas pastorales, lo que no obsta para que las cuestiones temporales adquirieran también una gran importancia en momentos clave de la relación Iglesia-Estado, por ejemplo cuando tuvo lugar la invasión estadunidense que obligó a dictar medidas drásticas que afectaban los bienes del clero. Precisamente de estos dos ámbitos -espiritual y temporal-manejados por la Iglesia nos ocuparemos en las siguientes páginas con el fin de expresar las intenciones de la potestad eclesiástica en la folletería publicada entre 1837 y 1851 .

Múltiples fueron las modalidades temáticas de los folletos: los novenarios, los triduos y los quinarios, las oraciones específicas para cada santo, los sermones marianos, las constituciones y reglas de las diversas congregaciones, las cartas pastorales, las órdenes religiosas, la teología y puntos de doctrina, los catecismos, los informes y circulares, los edictos y las noticias parroquiales, constituyen un rico material de estudio de donde se puede desentrañar el aspecto meramente religioso de la Iglesia. Por principio nos ocuparemos del reflejo espiritual impreso en los folletines, es decir, haremos referencia a la órdenes religiosas, las celebraciones, los sermones, el culto mariano y de los santos, así como lo relativo al dogma.

Es pertinente señalar que la acción del clero fue fundamental en la difusión de los principios religiosos, y que lo relativo a él se vería reflejaclo en la folletería. Los jesuitas se convirtieron en la preocupación más recurrente de sus defensores y de sus detractores. La propia historia de la Compañía de Jesús había marcado en la conciencia de los novoshispanos y, más tarde, de los mexicanos, la importancia de la orden que por disposición oficial había sufrido persecución, se le había decretado la expulsión y, según conviniera a los intereses estatales, había conseguido su restitución. Los jesuitas provocaron, según podemos deducir de la producción folletinesca, una gran polémica dentro de la sociedad decimonónica que reconocía, además de la propia labor espiritual de la orden, las aportaciones culturales realizadas tiempo atrás y que, a la vez, eran sujeto de crítica por parte de quienes no comulgaban con la manera de proceder de ese instituto religioso. A tal grado era importante el asunto que no únicamente los autores nacionales se ocuparon de ellos, sino que se echó mano de extranjeros para defensa o acusación de los discípulos de Ignacio de Loyola, y los escritos relativos circularon en forma de folletos para una mayor difusión del pensamiento.

Sin duda que la misma importancia de su presencia o ausencia hizo que un 
mayor número de publicaciones se ocuparan de ella, y que franciscanos y carmelitas, por citar a los otros más aludidos, quedaran eclipsados por la presencia siempre relevante de la institución ignaciana. No obstante, los descalzos y los discípulos de San Francisco también se expresaron en pocas páginas al imprimir sus capítulos, constituciones y reglas, y nos dejaron una manifestación diferente que habla de su organización interna y que, en ocasiones, se refiere a polémicas habidas con el gobierno por la posesión de bienes. Las otras órdenes que también tuvieron una gran actividad en México, agustinos, dominicos o filipenses, parecieron mantenerse en clausura sin dejar huella aparente en la folletería, ausencia que es una incógnita a despejar. A diferencia de éstos, los seminarios y colegios religiosos se expresaron en este tipo de impresos, y la diversidad de noticias sobre ellos nos revela su presencia en el territorio nacional: Oaxaca, San Luis Potosí, Zacatecas, Durango, Sonora, Puebla, Morelia y Guadalajara hablan de su importancia.

De la misma manera las monjas, dentro de este mundo editorial, adquirieron un sitio relevante. Clarisas, capuchinas y dominicas, principalmente, desfilan ante nosotros; publican sus biografias, ofrecen su nombre y apellido y dan a conocer las virtudes de la vida religiosa a través de quienes fueron consideradas las mejores o quienes pudieron costear e imprimir su propia historia. Reflejan, en cierto sentido, el mundo femenino que prevaleció en el siglo XIX, pues una opción para la mujer era, sin duda, la vida conventual en sus diversas modalidades. $^{7}$

La conmemoración del calendario religioso dio lugar a una dinámica actividad por parte del clero secular y regular. La vida de aquel tiempo transcurría inmersa entre la inestabilidad política, la incapacidad económica y la inseguridad social, lo que no impedía que las conmemoraciones católicas fuesen solemnizadas con gran algarabía en ciudades, pueblos y barrios, que se vestían de fiesta con cualquier pretexto. La Virgen se constituyó en el principal motivo de recordación, seguida de la Semana Santa que tanta tradición tenía y tiene en la vida de los mexicanos. Cada día era un motivo de celebración en los que se expresaba la devoción al santo patrón en fiestas impregnadas de santidad y frivolidad y en las que, en algunos casos, se aprovechó para hacer alusión a la situación reinante en el país. ${ }^{8}$ Los folletos guardan en sus páginas una rica tradición del calendario católico que de otra manera hubiera desaparecido con el paso de los años, y revelan la importancia de los festividades religiosas que tuvieron lugar, principalmente, en México, Guadalajara, Puebla, Oaxaca, Morelia, Querétaro y Durango, sitios en clonde se imprimieron la mayor parte de las publicaciones de esta índole.

${ }^{7}$ Las poblaciones que en mayor número publicaron cuestiones relativas a las órdencs religiosas fueron: México, Guadalajara, Querétaro, Puebla, Guanajuato, León y Chihuahua.

${ }^{8}$ Destaca en este sentido el sermón pronunciado por fray Ignacio Sampallo. En él, además de hacer una exhortación a defender la religión, se habla de la posible pérdida de la nacionalidad si no se repele la agresión estadunidense. Fray Ignacio Sampallo, Sermón, 1847. 
Sin duda la organización de las fiestas conllevó, necesariamente, a la preparación de sermones, pues daban motivo al predicador para narrar la vida y las cualidades de Jesús, la Virgen o el santo patrón. En ellos se plasmaba el sentir respecto a las principales figuras del cristianismo. La profesión de las monjas -clarisas, capuchinas y dominicas-, las ceremonias luctuosas o las celebraciones nacionales también servían de tema de inspiración. El publicar las homilias tenía una clara intención: hacerlas circular más allá del estricto ámbito en que habían sido pronunciadas, dar a conocer el pensamiento del autor, ejercer influencia en los sectores que tuvieran acceso al mismo y combatir, al mismo tiempo, cualquier postura que atentara contra la posición de la Iglesia. En este sentido, con el pretexto fútil de la festividad patronal, se pretendía defender el espacio en que siempre había transcurrido el ser y quehacer eclesial y, por tanto, enfrentar el poderío cada vez más sólido del Estado. Esta doble intención se encuentra en el contenido mismo del sermón, pues los títulos únicamente hacen referencia a la Virgen, principalmente a la de Guadalupe o a la Purísima Concepción, seguidos en importancia por los de Jesucristo, San Antonio de Padua, San Francisco de Asís, San Felipe Neri, San Luis Gonzaga, San Pedro y San Pablo, manifestando con ello qué solemnidades tenían un mayor revestimiento. ${ }^{9}$

9 Los años de mayor producción sermonaria, según revelan los fondos estudiados para cste periodo, son: $1839,1850,1845,1837$ y 1851 , el orden de los años está en relación con la producción. Los sitios que mayor número de sermones
Otra manera de expresar el culto a los santos y el culto mariano lo encontramos en los panegíricos, las historias de vida, los sonetos, los milagros, las novenas, los triduos, los quinarios, las oraciones, las saetas, los cancioneros, las encíclicas, las poesías y las indulgencias, que nos hablan de la arraigada religiosidad del pueblo mexicano que en la lectura y el rezo de los folletines encontró - y aún encuent ra-una manera segura de solicitar el favor divino y entrar en contacto con la potestad celestial. En este tipo de literatura, no escrita únicamente por religiosos, podemos también descubrir la popularidad de ciertos santos, que trasciende incluso hasta la época presente, como San José, San Antonio de Padua, San Miguel Arcángel, y de las diversas advocaciones de la Virgen. ${ }^{10}$ Junto a estas figuras hoy en día presentes, la "eficacia" de otros santos pareció desvanecerse con los años; no obstante esa pérdida, gracias a la folletería los rescatamos y nos acercamos a un santoral que formó parte de la de-

publicaron fueron: Guadalajara, Querćtaro, México, Oaxaca, Puebla, Zacatecas, Durango, San Luis Potosi y Atlixco. Esta diversidad de poblaciones refleja cuán importante resultaba publicar los sermones.

${ }^{10}$ Cabe mencionar aquí que además de la popularidad de la Virgen de Guadalupe y la Purísima Concepción, otras advocacciones fueron objeto de culto. Así, correspondió a la Virgen de los Dolores, la Divina Infantita, de los Ángeles, de Zapopan, de la Merced, de los Remedios, del Pueblito, de la Cueva Santa, de has Victorias, de Atlixco, del Refugio, de la Defensa, de la Luz y de Atocha. Los sitios de impresión cle los folletos muestran la misma diversidad de las advocaciones: México, Guadalajara, Puebla, San Luis Potosí, Oaxaca, Morelia, Orizaba, San Juan de los Lagos y Querétaro. 
voción del pueblo mexicano del siglo XIX, y al que otros santos "más eficientes" eclipsaron su poder. Los nombres de Eleazaria y Delfina, Girolamo, Nicolás Tolentino, Filomena, Adeodato o Eduviges fueron importantes en su momento, ofrecieron sus favores a quienes los invocaron y quedaron impresos en tinta y papel con sus rezos, virtudes y milagros.

En cuanto al aspecto meramente doctrinario de la Iglesia, lo podemos rescatar a través de las encíclicas, los edictos y las circulares, ${ }^{11}$ los aranceles y las congruas, las cartas pastorales, las cuestiones teológicas, ${ }^{12}$ el derecho canónico, la organización de la Iglesia ${ }^{13}$ y los catecismos $;{ }^{14}$ son materiales que

${ }^{11}$ Se refieren principalmente a cuestiones tales como: jesuitas, provisión de curatos, censura de libros, misiones, clero regular, obispos, calendario religioso e indulgencias. La ciudad de México se constituyó en el principal centro de impresión de estos asuntos religiosos.

12 Los asuntos relativos a teología y puntos de cloctrina hacen alusión, principalmente, a: censura de libros, mandamientos, ejercicios espirituales, culto y liturgia, indulgencias, meditación, penitencia, sacramentos, la Virgen y los ángeles.

${ }_{13}$ Respecto de la organización de la Iglesia, la temática más recurrente fue: la provisión de cargos, los asuntos de regulares y las cofradías, siendo la ciudad de México la plaza en donde se imprimió el mayor número de folletos sobre este tema.

${ }^{14}$ Es importante señalar aquí que los catecismos en español y lenguas indigenas -mixteco, mexicano y maya- constituyeron un renglón importante en la folleteria de esta época. Los conceptos más elementales de la religión fueron publicados en forma de preguntas y respuestas y revelan el interés por hacer llegar a los diversos sectores de la población el. conocimiento de la religión. También es importante señalar que los lugares de edición fueron: Puebla, México, Mérida y Guadalajara. ofrecen, de alguna manera, cuestiones relativas al dogma y a la fe. Escritos venidos desde la más alta jerarquía hasta autores no muy connotados, encontraron en los folletos un medio de manifestar y expresar las distintas preocupaciones de la institución eclesial. Los más de ellos se encargan de cuestiones estrictamente religiosas que exigían de los creyentes una fiel observancia de los preceptos católicos y una guía en la conducta personal. ${ }^{15}$ Mas no únicamente se reveló la potestad eclesial en este sentido. Aprovechó esta clase de documentación para defender los intereses terrenales de la institución cristiana, llegando a ser una denuncia continua contra el proceder del Estado que cada día quería excluirla de exenciones y privilegios conquistados en la época colonial, como lo veremos más adelante.

Si bien lo hasta aquí señalado se refiere a la preocupación de la Iglesia por salir de los templos y dar a conocer su doctrina y sus modelos de vida, otros intereses también se expusieron en la folletería y tuvieron que ver con asuntos más terrenales, más temporales. La amenaza de los diversos gobiernos nacionales fue una constante que contrarió los intereses de la corporaciōn fundada por Cristo. $\mathrm{Su}$ intención radicó esencialmente en someter la potestad eclesial bajo su dominio,

${ }^{15}$ Los dogmas de la religión, la censura de libros, la oposición a las sectas, el pago de diezmos, los deberes de los religiosos, entre otros, fueron temas recurrentes en la folletería agrupada en: aranceles/congruas/obvenciones; cartas pastorales; circulares/edictos episcopales; tocumentos pontificios, y teología/puntos de doctrina. 


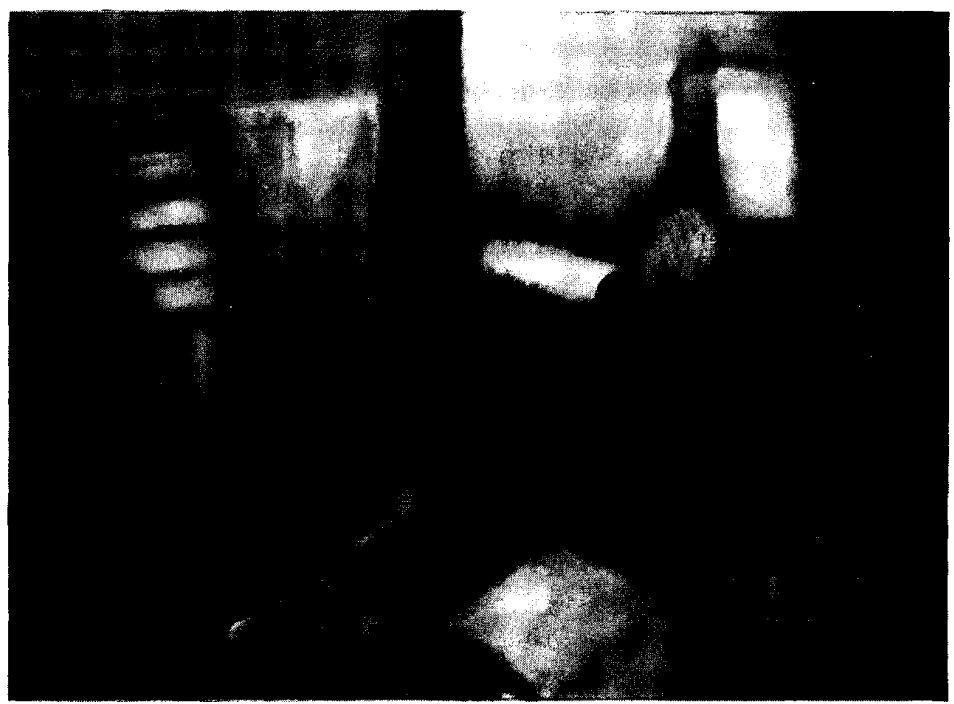

privándola de fueros y privilegios, exigiéndole préstamos, vendiendo sus bienes, a lo que la Iglesia no estaba dispuesta. Los años comprendidos entre 1837 y 1851 muestran una clara tendencia a disminuir el poder eclesial. Si en el año de 1837 la Iglesia estuvo dispuesta a ofrecer un préstamo al gobierno para sufragar los gastos estatales, ${ }^{16}$ diez años más tarde no presen-

16 Como un ejemplo de esta disposición tenemos el folleto publicado por el Arzobispado de México. En él, según nos refiere el Catálogo de la Colección Lafragua, se examina la petición del gobierno relativa a que la Iglesia le dé crédito para obtener un empréstito en condiciones favorables; se considera licita y respetuosa la petición y resuelven acceder a la solicitud autorizando a hipotecar hasta 750000 pesos de los bienes de las corporaciones sujetas a la jurisdicción del Ordinario diocesano. Arzobis- tó la misma disposición, y ello está en directa proporción con la agresión estatal y con la disminución en la capacidad económica de aquélla.

Los títulos de los folletos agrupados en documentos políticos, polémicas y bienes de la Iglesia, muestran el interés de esta corporación por defender los espacios que había logrado conquistar a lo largo de los tres siglos de colonia, y que la independencia comenzó a vulnerar. La amenaza de desamortizar y nacionalizar los bienes inmuebles alertó a la Iglesia para diseñar una estrategia que le permitiera conservar su patrimonio y justificar su proceder frente a las exigencias de las

pado, Dictamen, 1837. Véase Moreno, Catálo go, 1975 , referencia 3607 . 
autoridades que, cada día, se esforzaban en disminuir su injerencia en la sociedad. ${ }^{17}$ De la misma manera, cuando el amago de la tolerancia campeó el escenario nacional, la Iglesia sacó a relucir una importante producción folletinesca de oposición a las intenciones del gobierno, que no sólo tenían que ver con la aceptación de otras religiones, sino que tambien involucraban cuestiones tales como los diezmos, la provisión de cargos eclesiásticos, los préstamos al gobierno, los privilegios, las constituciones politicas y los cementerios. Frente a todos ellos, la Iglesia reaccionó con prontitud y fuerza, pues no estaba dispuesta a disminuir su poder; los bienes y la tolerancia fueron los puntos más polémicos de discusión.

Los bienes eclesiásticos codiciados por el gobierno eran una vieja historia en la que, a final de cuentas, se expresaba el enfrentamiento entre las dos instituciones que se disputaban el poder en la nación mexicana. No hay que olvidar que el Estado mexicano, desde muy temprana época, comenzó a acumular una inmensa deuda que le impedía tener finanzas sanas, y que, frente a los agobios nacionales, se vio forzado a mirar en las propiedades de la Iglesia una manera de solventar sus necesidades más apremiantes. La institución católica mantuvo una posición tendiente a retener lo acumulado

17 Desde que Valentín Gómez Farías intentó las reformas liberales en 1833, el deseo de despojar a la Iglesia de sus bienes estuvo latente, y en diversas ocasiones se dictaron medidas en ese sentido. Cabe recordar aquí la problemática derivada del fondo piadoso de las Californias, o las disposiciones dadas en 1847. por siglos y no cejó en sus esfuerzos para exhibir sus prerrogativas y exigir sus derechos aunque, en ocasiones, como ya se señaló, estuvo dispuesta a cooperar con el gobierno.

El análisis del material nos revela que, de muy diversas maneras, los eclesiásticos expresaron su protesta, ya fuera en las cartas pastorales, en edictos y circulares o en escritos redactados para tal fin. En esta tarea defensiva la Iglesia jugó sus mejores cartas, se apoyó en el pasado, apeló a los más diversos talentos, tradujo las obras de autores extranjeros, comprometió a sus pastores e involucró a connotados políticos que estuvieron dispuestos a enarbolar sus intereses. ${ }^{18}$ Estos folletos, los más polémicos, son la prueba más clara del otro interés que manejaba la Iglesia: que, según su propia concepción, al perder su poderío económico aminoraría su presencia en la sociedad mexicana y, necesariamente, vería afectada su hegemonía ideológica.

Dos momentos importantes clestacan respecto de la defensa de los

18 Basta mencionar aquí los folletos de Balmes, Observaciones, 1842, en donde el autor defiende el derecho del clero a tener propiedades adquiridas justamente y exigir de la sociedad los medios para subsistir, y de Rodríguez, Rectificación, 1845, en que se hace referencia al decreto del Senado sobre revisión de contratos de enajenación de bienes del fondo piadoso de las Californias; asienta que el obispo no reclama propiedad sino derecho de las misiones a dichos bienes, que no se pueden considerar bienes nacionales, puesto que por reales cédulas siempre se consideraron ramos ajenos a la Hacienda pública. Impugna a quienes lo consideran involucrado en el negocio por intereses personales. Véase Moreno, Catálogo, 1975, referencias 4192 y 4831 , respectivamente. 
asuntos temporales de la Iglesia: En 1847 , cuando a raíz de la invasión estadunidense se dictaron medidas relativas a sus bienes; $y$ en ese mismo año y entre $1850-51$, cuando se abordó la posibilidad de introducir la tolerancia religiosa. Frente a estos peligros la Iglesia reaccionó con vigor.

Es necesario recordar los acontecimientos que se sucedieron en el país para comprender la actuación de la Iglesia durante la invasión estadunidense. Si bien en 1846 las autoridades mexicanas no midieron la amenaza extranjera en su justa dimensión, para enero del siguiente año se vieron en la necesidad de dictar medidas drásticas que afectaban el poderío económico de la Iglesia, pero que no lograron ponerse en marcha dada la capacidad de la entidad religiosa para movilizar a sus fieles y para convencer a la población de los atropellos de un gobierno impío, como era el de Valentín Gómez Farías. Sin embargo, el problema no paró allí, y ante las urgencias gubernamentales, en el mes de mayo se dictó una nueva disposición que afectó necesariamente a la Iglesia, pues se le pedía su cooperación, por medio de sus bienes, para poder continuar la guerra. ${ }^{19}$ La reacción no se hizo esperary, al igual que en el mes de enero, se siguieron un inmenso número de

19 El ministro Luis de la Rosa fue quien dictó las nuevas disposiciones que contrariaban los intereses de la Iglesia. Según la circular de De la Rosa los estadunidenses eran enemigos comunes del gobierno y de la Iglesia, por lo que esta última debía ofrecer ayuda a las autoridades vendiendo parte de sus bienes para facilitarle dinero a las autoridades civiles. protestas en las que se combatía la disposición gubernamental.

Para dar una idea de la reacción, basta ver el elevado número de folletos publicados en ese año referentes únicamente a este problema e impresos en diversas poblaciones, lo que habla del interés por dar a conocer la oposición de la Iglesia a las disposiciones del gobierno. Los autores de estas protestas no sólo fueron miembros de la alta jerarquía eclesiástica, civiles y religiosos comunes también emprendieron la defensa. Alrededor de 90 publicaciones se imprimieron con el polémico tema de los bienes eclesiásticos. Los más de ellos basaron su argumentación en la falsa riqueza que se le atribuía a la institución, en la ilegalidad del gobierno al usurpar sus bienes, en la soberanía de su poder, en el desconocimiento de las hipotecas o enajenaciones que dispusiera el gobierno y en los problemas que derivarían de la aplicación de las leyes y decretos. La extensa producción de estos impresos, en distintos puntos del país, son la prueba más contundente de la capacidad eclesiástica para tratar de convencer de la viabilidad de sus protestas; manifiestan también el compromiso de sus fieles para con la institución y la trayectoria misma de la Iglesia en la defensa de sus intereses, y nos revelan además quiénes de los impresores estaban de acuerdo con el proceder de la institución eclesiástica.

En cuanto al problema de la tolerancia, éste se agudizó con el tiempo. Si las diversas constituciones del país habían protegido a la religión católica y la habían declarado única, la falta de solidaridad de la Iglesia para con las 
demandas del gobierno llevó a este último a manejar la amenaza de permitir otros cultos. Este hecho dio pie, de nueva cuenta, a la institución fundada por Cristo para levantar su voz y contrariar los intereses de las autoridades. El año de 1847 y los que siguieron hasta 1851 revelan cuán latente estuvo este problema y cómo se dejaron escuchar distintas voces, desde las más diversas poblaciones, en contra de esta posible decisión. Es importante hacer notar que, a diferencia de otras cuestiones, en la defensa de la intolerancia, las diversas comunidades católicas encabezadas por los curas pueblerinos, publicaron sus escritos de protesta y señalaron cuán peligroso le resultaría al país la aceptación de otros cultos. Los pies de imprenta de los folletos revelan la diversidad de comunidades que se pronunciaron contra la posibilidad de la tolerancia. Ante todo manejaron la probable desunión nacional que se desprendería necesariamente de la aceptación de otras religiones. Reconocían que la fe católica había sido un vínculo que había mantenido unido al país y que el deseo nacional era contrario a la tolerancia, como se manifestaba en los folletos.

Si bien lo hasta aquí señalado es un rápido recuento de lo más sobresaliente de la producción eclesiástica en opúsculos, nos permite sin embargo destacar las dos funciones que tuvieron ese tipo de impresos en la intención eclesiástica, que revelan a un mismo tiempo su interés espiritual y material. Asimismo, el análisis nos permitió acercarnos a la actuación gubernamental, que cada día fue cercando a su contrincante con la abierta inten- ción de despojarla del poder-respal. dado por los numerosos bienes inmuebles acumulados en su tránsito vi. rreinal-y, al mismo tiempo, conocer la reacción de una institución que no únicamente fincaba sus expectativas en asuntos celestiales. Los ataques que recibió de parte del Estado no atenta. ron en ningún momento contra el dog. ma, sino que tuvieron un carácter más bien práctico: restarle poder económico, utilizar sus recursos y, a la vez, despojarla del monopolio espiritual que había logrado instaurar en el país. Sin duda que en el aspecto económico, con el paso de los años, se consiguió mucho, no así en lo espiritual, pues la presencia corporativa de Cristo era una dificil realidad a derrotar en una sociedad que creía más en los clérigos que en los políticos, y cuya devoción era la prueba más patente de su adhesión a la Iglesia.

La revisión de los títulos nos permitió hacernos, las más de las veces, una idea clara del contenido de los folletos, no obstante que, por ejemplo en los sermones, la intitulación únicamente se refiere al aspecto espiritual, y no trasluce el contenido político que este tipo de textos poseyó. Reveló, asimismo, el fervor de los mexicanos para con sus santos predilectos y manifestó la esperanza de un pueblo en sus creencias cristianas, así como las ocupaciones y preocupaciones de una Iglesia en una etapa de transición. Es importante mencionar que los pies de imprenta fueron muy reveladores en cuanto a los editores comprometidos con la institución católica -los que seguramente se enriquecieron con este oficio-, los sitios de impresión, o los 
años en que se vuelve recurrente un problema. Respecto de los editores podemos señalar que, en la ciudad de México, los talleres de Luis Abadiano y Valdés, José Mariano Lara, Vicente García Torres, Ignacio Cumplido, Ignacio Galván, Rafael Rafael y La Voz de la Religión fueron las que, en mayor cantidad, difundieron la problemática de la Iglesia. En Guadalajara, Dionisio Rodríguez y Manuel Brambila se dieron a la tarea de difundir el sentir y pensar eclesiásticos, casi de manera exclusiva. En Puebla, Juan N. del Valle y Atenógenes Castillero; en Morelia, Ignacio Arango, y en Oaxaca, Ignacio Rincón, cooperaron de alguna manera en la difusión de los principios e intereses cristianos. ${ }^{20}$

La variada temática refleja también la diversidad de campos en que se manejó la institución católica, pues al tiempo que imprimía oraciones, publicaba asuntos referentes a las órdenes religiosas, seminarios, bienes de la Iglesia, tolerancia, o disposiciones papales. La producción de folletos eclesiásticos mostró, en última instancia,

${ }^{20}$ Otras imprentas que sobresalieron en la ciudad de México fueron: la Imprenta Del Águila, dirigida por José Ximeno, J. Ojeda, Imprenta Católica, J. M. Rivera y la de la Sociedad Litera. ria. También es pertinente señalar que en otros sitios de la república también se imprimieron cuestiones relativas a la Iglesia. En Guanajuato destacaron las imprentas de F. Conejo y J. E. Oñate; en Durango, la Imprenta del Gobierno; en Aguascalientes, José María Chávez; en Orizaba, J. N. Naredo. Es necesario mencionar que esto es una aproximación en cuanto a los sitios de impresión, y únicamente se señalaron aquellas imprentas que fueron más recurrentes en el reporte de la folletería eclesiástica. cuán importante fue esta vía para exponer la postura de la corporación cristiana, pues la utilizó para expresar preceptos, mover conciencias y consolidar adeptos.

\section{BiBliografía}

-Arzobispado de México, Dictamen de la comisión y acuerdo del Ilmo. Cabildo metropolitano de México sobre hipotecarlos bienes eclesiásticos para el empréstito que solicita el supremo gobierno, Luis Abadiano y Valdés, México, 1837, 28 pp.

-Balmes, Jaime, Observaciones sociales, políticas y económicas sobre los bienes del clero, reimpreso en la Oficina de Manuel Brambila, Guadalajara, 1842, 76 pp.

-Connaughton, Brian, Ideología y sociedad en Guadalajara (1788-1853), CNCA, México, 1992.

-Moreno Valle, Lucina, Catálogo de la Coleccción Lafragua 1821-1853, Instituto de Investigaciones Bibliográficas-UNAM, México, 1975.

-Muriá, José María, "Folletería mexicana del siglo XIX", Secuencia, núm. 6, septiembre-diciembre, 1986.

-Rodríguez de San Miguel, Juan, Rectificación de graves equivocaciones en que inciden los señores terceros poseedores de los bienes del fondo piadoso de las $\mathrm{Ca}$ lifornias, con respecto al reverendo obispo y a su apoderado, Imprenta de Lara, 1845, México, $16 \mathrm{pp}$.

-Sampallo, Ignacio, Sermón políticoreligioso de María Santísima de Guadalupe que predicó en la santa iglesia parroquial de San Luis Potosí, en el día de acción de gracias de la conclusión del novenario llamado de las flores, el R. P. ex definidor, lector de sagrada teología y presidente in capite del convento fray..., Imprenta de Escontría, San Luis Potosí, 1847, 11 pp. 